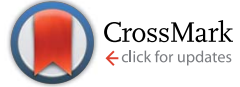

Cite this: J. Mater. Chem. A, 2017, 5, 11634

Received 12th January 2017

Accepted 8th February 2017

DOI: $10.1039 / \mathrm{cta00409e}$

rsc.li/materials-a

\section{Elucidating the alkaline oxygen evolution reaction mechanism on platinum $\uparrow$}

\author{
M. Favaro, ${ }^{\text {abc }}$ C. Valero-Vidal, ${ }^{\text {ad }}$ J. Eichhorn, ${ }^{c}$ F. M. Toma, ${ }^{c}$ P. N. Ross, ${ }^{\text {e }}$ J. Yano, ${ }^{\text {bf }}$ \\ Z. Liugh ${ }^{\text {gh }}$ E. J. Crumlin*ad
}

\begin{abstract}
Understanding the interplay between surface chemistry, electronic structure, and reaction mechanism of the catalyst at the electrified solid/liquid interface will enable the design of more efficient materials systems for sustainable energy production. The substantial progress in operando characterization, particularly using synchrotron based X-ray spectroscopies, provides the unprecedented opportunity to uncover surface chemical and structural transformations under various (electro)chemical reaction environments. In this work, we study a polycrystalline platinum surface under oxygen evolution conditions in an alkaline electrolyte by means of ambient pressure X-ray photoelectron spectroscopy performed at the electrified solid/liquid interface. We elucidate previously inaccessible aspects of the surface chemistry and structure as a function of the applied potential, allowing us to propose a reaction mechanism for oxygen evolution on a platinum electrode in alkaline solutions.
\end{abstract}

\section{Introduction}

With the world's energy utilization increasing, new solutions are required to satisfy the energy demand while minimizing the environmental impact. To meet this challenge, new technologies must be improved to achieve sustainable energy conversion and consumption., ${ }^{1,2}$ Fuel cells and electrolyzers ${ }^{3}$ constitute a promising candidate towards the clean conversion of chemical energy into electricity and electricity into chemical energy, respectively. However, their current use is still partially limited by several factors, such as the limited efficiency and stability of the low cost alternatives to platinum (Pt) for the electrocatalysis of oxygen reduction and evolution reactions (ORR and OER,

${ }^{a}$ Advanced Light Source, Lawrence Berkeley National Laboratory, One Cyclotron Rd, Berkeley, CA 94720, USA. E-mail: ejcrumlin@lbl.gov

${ }^{b}$ Joint Center for Artificial Photosynthesis, Lawrence Berkeley National Laboratory, One Cyclotron Rd, Berkeley, CA 94720, USA

${ }^{c}$ Chemical Sciences Division, Lawrence Berkeley National Laboratory, One Cyclotron Rd, Berkeley, CA 94720, USA

${ }^{d}$ Joint Center for Energy Storage Research, Lawrence Berkeley National Laboratory, One Cyclotron Rd, Berkeley, CA 94720, USA

${ }^{e}$ Materials Sciences Division, Lawrence Berkeley National Laboratory, One Cyclotron Rd, Berkeley, CA 94720, USA

${ }^{f}$ Molecular Biophysics and Integrated Bioimaging Division, Lawrence Berkeley National Laboratory, One Cyclotron Rd, Berkeley, CA 94720, USA

${ }^{g}$ State Key Laboratory of Functional Materials for Informatics, Shanghai Institute of Microsystem and Information Technology, Chinese Academy of Sciences, Shanghai 200050, People's Republic of China

${ }^{h}$ Division of Condensed Matter Physics and Photon Science, School of Physical Science and Technology, ShanghaiTech University, Shanghai 200031, China

$\dagger$ Electronic supplementary information (ESI) available. See DOI: $10.1039 / \mathrm{c} 7 \mathrm{ta00409e}$ respectively). ${ }^{4,5}$ In order to enhance the catalytic performance of next generation fuel cells and electrolyzers, it is necessary to obtain a comprehensive understanding of the chemistry and electronic structure of the catalyst and the reaction intermediates/ products under realistic operating conditions. ${ }^{6,7}$ In particular, Pt has been used as a model system to provide surface chemical and structural transformation insights under various (electro)chemical reaction environments. ${ }^{8-23}$ Ultimately, the scope of these studies is to expedite the development of novel and cost-effective catalysts with tailored physical/chemical properties, capable of achieving, if not surpassing, the Pt electrocatalytic performance. ${ }^{\mathbf{8 2 4 - 2 7}}$

Previous studies have been conducted to indentify the role of Pt oxides in the oxygen evolution reaction pathway (also known as oxygen discharge). ${ }^{\mathbf{8 2 4 - 2 6}}$ Krasilshchikov $^{\mathbf{2 4 , 2 6 , 2 8}}$ demonstrated that at high overpotentials the corresponding current density (Tafel slope $120 \mathrm{mV} \mathrm{dec}^{-1}$ ) depends exponentially on the thickness of the Pt surface oxide. Other studies report much higher Tafel slopes (up to $\left.160 \mathrm{mV} \mathrm{dec}{ }^{-1}\right)^{13,24,26}$ in both acidic and alkaline environments. Such an increase is often attributed to an increase of the surface oxide layer thickness and Pt dissolution..$^{13,15-26,29}$ In alkaline media, the reversible binding of a hydroxide ion $\left(\mathrm{OH}^{-}\right)$coupled to a one electron oxidation is thought to precede the removal of one proton and one electron to form surface oxide species. ${ }^{30}$ This hypothesis has been mostly supported so far by surface structure and chemical characterizations far from operando conditions, ${ }^{6,31,32}$ thereby limiting an unambiguous investigation of the role of Pt oxides in the oxygen evolution catalytic cycle. Moving towards realistic operating conditions, Arrigo et al. recently studied Pt nanoparticles deposited on an acidic-polymer membrane using ambient pressure X-ray photoelectron spectroscopy (APXPS) in a humidified (solid/gas interface) environment. ${ }^{27}$ The authors found that the 
first stage of Pt oxidation involves the formation of a surface Pt oxide ${ }^{27,33}$ where atomic oxygen $(\mathrm{O})$ is weakly bound to $\mathrm{Pt}(\mathrm{Pt}-\mathrm{O}) .^{27,34}$

However, the detailed chemistry, structure, and dynamics of the surface oxide(s) on Pt at an electrified solid/liquid interface as a function of the applied potential and during oxygen evolution as a function of time still remains unclear. A definitive chemical speciation of such species and their role in the reaction pathway has not been completely achieved yet, in particular on Pt surfaces in alkaline conditions.

To achieve a molecular-level comprehension of the OER mechanism, we studied a polycrystalline Pt electrode surface under anodic conditions in an alkaline electrolyte, by means of operando APXPS performed with "tender" X-rays $(h \nu=4 \mathrm{keV})$ directly at the electrified solid/liquid interface. ${ }^{35,36}$ We report the speciation of porous Pt surface oxides as a function of applied potential, thereby elucidating the differences between thermodynamic predictions (Pourbaix diagrams) ${ }^{37}$ and the actual surface composition under polarization. Moreover, we study the Pt surface chemistry as a function of time during oxygen evolution, thereby observing the evolution of the different $\mathrm{Pt}$ oxidation states (as well as their spatial localization in the nearsurface region) under non-equilibrium conditions (initial transient) and upon reaching steady state conditions. Based on these findings, we propose an OER mechanism in terms of a catalytic (Tolman) cycle ${ }^{38}$ for the various oxidized Pt species. We show that the rate-determining step is constituted by activated $\mathrm{Pt}$ sites selectively binding $\mathrm{OH}^{-}$. In addition, by coupling the experimental results with numerical simulations of the photoelectron intensity, we reveal that the active sites during OER are located in the sub-surface region, whereas Pt oxides such as $\mathrm{Pt}^{(\mathrm{II})} \mathrm{O}$ and $\mathrm{Pt}^{(\mathrm{IV})} \mathrm{O}_{2}$ are present in the high-surface outer layer and are not actively contributing to the oxygen evolution.

\section{Results}

\section{Probing the solid/liquid interface}

Operando measurements (defined here as a function of the applied potential at a solid/liquid interface) were performed on a polished polycrystalline Pt working electrode (WE) in $1.0 \mathrm{M}$ $\mathrm{KOH}$ electrolyte interface using "tender" X-rays $(h \nu=4 \mathrm{keV})$ for APXPS, ${ }^{35-40}$ as depicted in Fig. 1a. The "dip and pull" procedure $^{35-40}$ enabled us to simultaneously probe $\sim 21 \mathrm{~nm}$ of the aqueous electrolyte and $\sim 10 \mathrm{~nm}$ of the Pt WE using photoelectron spectroscopy, while undergoing electrochemical reactions at the solid/liquid electrified interface. In our threeelectrode electrochemical cell, ${ }^{34}$ we used a polycrystalline Pt foil as the counter electrode (CE) and a $\mathrm{Ag} / \mathrm{AgCl} / \mathrm{Cl}_{(\text {sat. }}{ }^{-}$as the reference electrode (RE). All potentials are reported with respect to this RE, unless otherwise stated.

In order to study the evolution of the current density as a function of applied potential and time (by holding the applied potential at a constant value), we performed both cyclic voltammetry (CV) and chronoamperometry (CA) measurements (Fig. 1b), respectively. We explored different potentials along the anodic branch of the CV from open circuit potential (OCP) up to $+900 \mathrm{mV}$ (OER conditions, see Fig. 1b). In addition, the reversibility of the $\mathrm{Pt}$ surface chemistry and structure was assessed by returning back to OCP after OER conditions, defined as "OCP after OER". The overpotential $(\eta)$ has been computed using the standard Nernstian potential for water oxidation for a $\mathrm{pH}$ equal to $13.9\left(+205 \mathrm{mV} v s\right.$. $\left.\mathrm{Ag} / \mathrm{AgCl} \mathrm{Cl}_{\text {(sat.) }}{ }^{-}\right)$.

To approximate the current density of the thin electrolyte layer under operando conditions formed by the "dip \& pull" procedure, we conducted a separate electrochemical experiment that preserved the same "dip \& pull" geometries, we masked the bottom of the electrode that was immersed in the bulk electrolyte and compared to an unmasked electrode (see schematization reported in ESI Fig. $1 \dagger$ ). The thickness of electrolyte layer on the Pt WE was equal to $21.3 \mathrm{~nm}$. This value was calculated via the inverse Beer-Lambert relation using the attenuation of the Pt $4 \mathrm{f}$ core level signal passing from hydrated conditions (saturated environment before "dip \& pull” procedure) to the final solid/liquid interface configuration..$^{31,36} \mathrm{We}$ have determined that a bulk (unmasked) current density of about $1.0 \mathrm{~mA} \mathrm{~cm}^{-2}$ at $+900 \mathrm{mV}$ (overpotential $\eta=+695 \mathrm{mV}$, OER conditions) corresponds to $c a .0 .3 \mathrm{~mA} \mathrm{~cm}^{-2}$ in the nanometric-
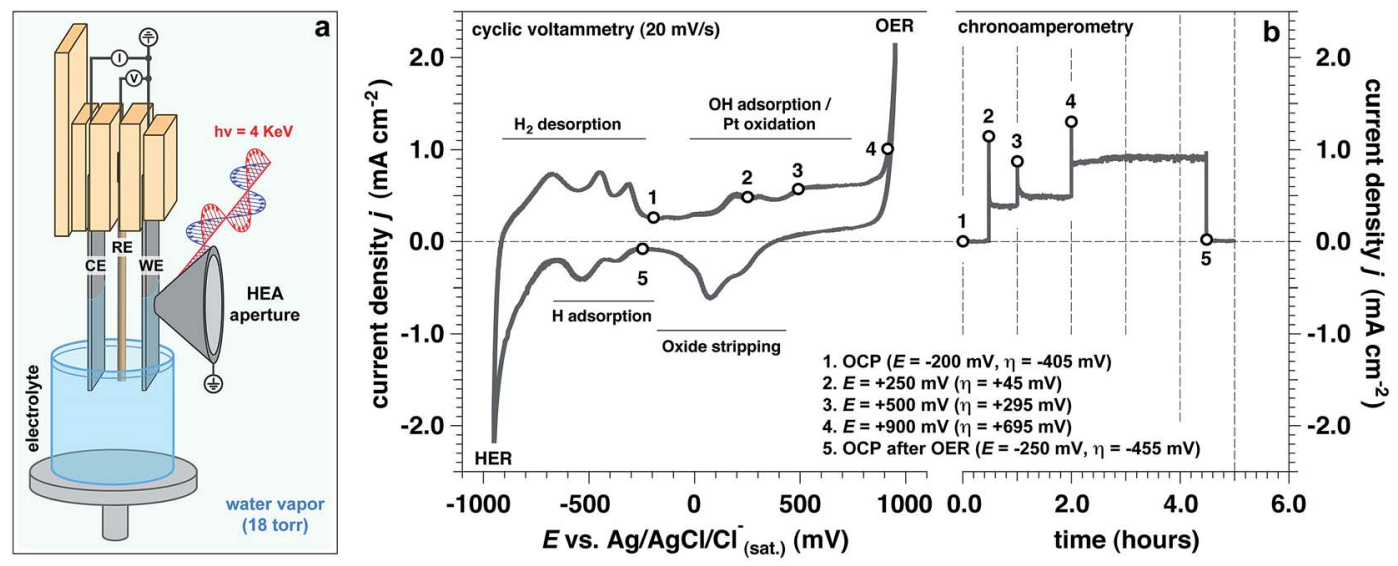

Fig. 1 Experimental set-up and electrochemical characterization. (a) Three electrode electrochemical set up, used in this work (CE: counter electrode; RE: reference electrode; WE: working electrode, HEA: hemispherical electron analyzer); (b) cyclic voltammetry (20 $\mathrm{mV}^{-1}$ ) and chronoamperometry for a polycrystalline Pt electrode in alkaline conditions (measured $\mathrm{pH}$ 13.9) at room temperature and for a water pressure in the chamber equal to 18 Torr (OCP: open circuit potential; HER: hydrogen evolution reaction; OER: oxygen evolution reaction). 
thick electrolyte layer on the WE surface (ESI Fig. 1b†). This is due to the predominant contribution of the current rising from the part of the WE immersed in the bulk electrolyte. This observation was reaffirmed by electrochemical impedance spectroscopy (EIS) measurements which extracted the polarization resistance $\left(R_{\mathrm{p}}\right)$ for the masked and unmasked configurations (see ESI Fig. 2 and 3, Tables 1 and 2 and Discussion 1 for further details $\dagger$ ). The ratio between the two configurations polarization resistances (unmasked to masked) is equal to 3.37, thereby confirming that the total current density associated with the thin electrolyte film was about a third of the overall measured current.

Upon establishing current flow within the nanometric electrolyte layer, we can use the XPS data in Fig. 2 to confirm the applied potential directly at the probing location..$^{35-39} \mathrm{O} 1$ s and $\mathrm{K}$ $2 \mathrm{p}$ core levels as a function of the applied potential are reported in Fig. 2a-c, respectively. In particular, Fig. $2 \mathrm{~b}$ reports a magnification of the $\mathrm{O} 1 \mathrm{~s}$ multipeak fitting procedure for the low BE tail. Notably, at different applied potentials, the area of the $\mathrm{OH}_{\text {sol }}{ }^{-}$(hydroxide ions in solution) and $\mathrm{K} 2 \mathrm{p}$ (solely depicting the $\mathrm{K}^{+}$ions in solution) spectral feature remains constant throughout the experiment. Indeed, the liquid phase water $(\mathrm{LPW}) / \mathrm{OH}_{\text {sol }}{ }^{-}$and $\mathrm{LPW} / \mathrm{K} 2 \mathrm{p}$ concentration ratio is equal to $51.4 \pm 2.1$ as the applied potential is changed from OCP to OER conditions (Fig. 2d). Our measurement is therefore in agreement with the expected value for a $1.0 \mathrm{M}$ electrolyte concentration, which is $\mathbf{5 5 . 5 1}$ water to one $\mathrm{KOH}$.

The binding energy (BE) trends of the $\mathrm{O} 1 \mathrm{~s} \mathrm{LPW}, \mathrm{OH}_{\mathrm{sol}}{ }^{-}$and $\mathrm{K} 2 \mathrm{p}_{3 / 2}$ core levels present in the liquid layer as a function of the applied potential is reported in Fig. 2 d. The BEs for elements in the electrolyte $\left(\mathrm{BE}_{\text {electrolyte }}\right)$ obey the relation:

$$
\mathrm{BE}_{\text {electrolyte }}=\mathrm{BE}^{0}-e E
$$

$E$ is the applied potential and $\mathrm{BE}^{0}$ is the $\mathrm{BE}$ measured in absence of an applied potential. According to eqn (1), the aforementioned core levels shift toward lower BEs with respect to the Fermi level of the sample (grounded to the analyzer, see
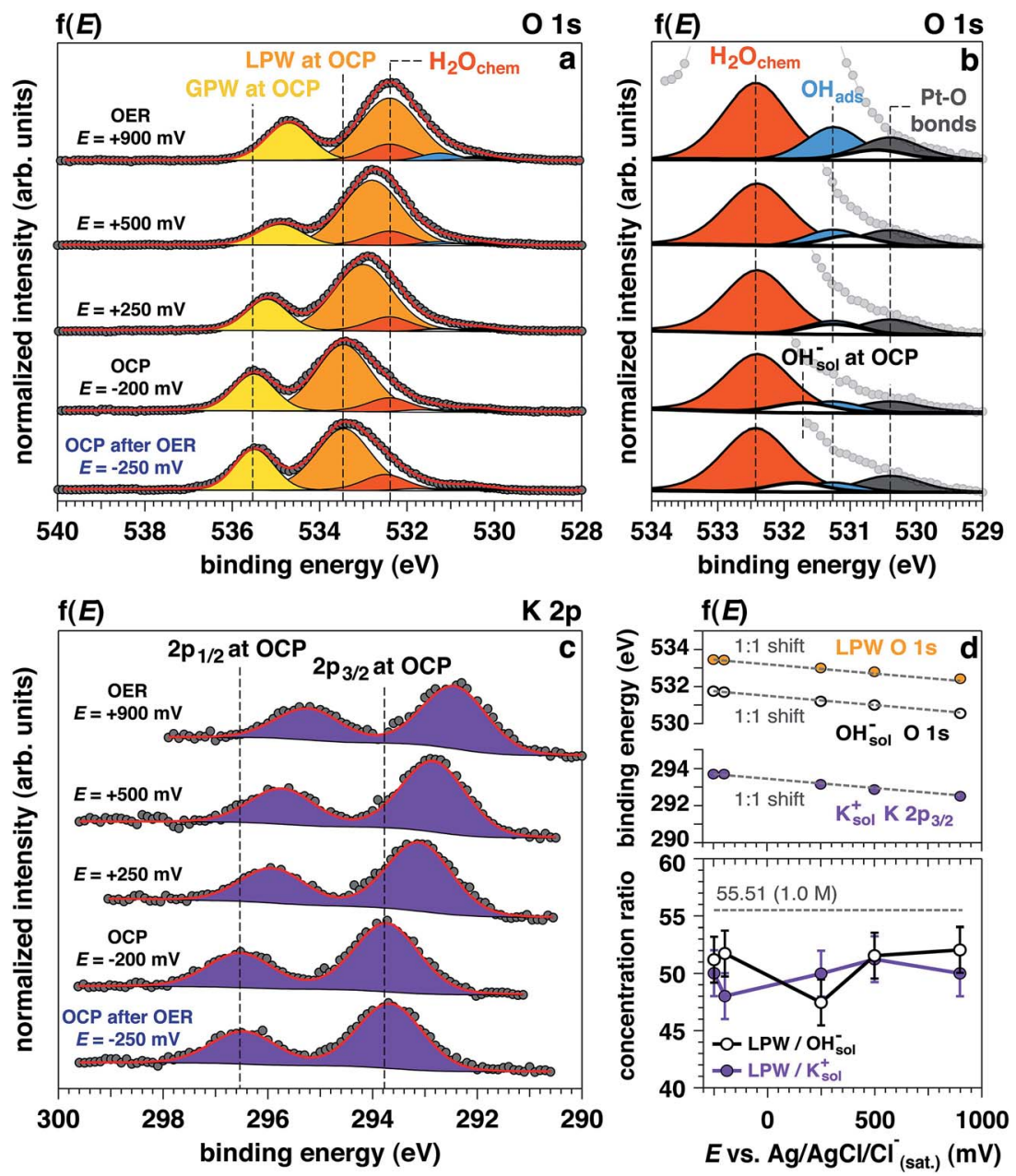

Fig. 2 Operando APXPS as a function of the applied potential. $(\mathrm{a}, \mathrm{b}) \mathrm{O}$ 1s photoelectron peak acquired at $4 \mathrm{keV}$ as a function of the applied potential $(f(E))$ to the working electrode (WE, from OCP to OER) and magnification of the low binding energy spectrum tail, respectively; (c) $K 2 p$ photoelectron peak acquired at $4 \mathrm{keV}$ as a function of the applied potential $(f(E)$ ) to the working electrode (from OCP to OER). (d) Reports the BE shifts of $\mathrm{LPW}, \mathrm{OH}_{\text {sol }}{ }^{-}$and $\mathrm{K}_{\text {sol }}{ }^{+}$core levels as a function of the applied potential $(f(E))$ and the ratio between the normalized $\mathrm{LPW}, \mathrm{OH}_{\text {sol }}{ }^{-}$and $\mathrm{K}_{\text {sol }}{ }^{+}$ integrated peaks areas, which shows the agreement with the expected value (OCP: open circuit potential; OER: oxygen evolution reaction; GPW: gas phase water; LPW: liquid phase water; $\mathrm{H}_{2} \mathrm{O}_{\text {chem }}$ : chemisorbed water; $\mathrm{OH}^{-}$ads: adsorbed hydroxyls). 
schematization reported in Fig. 1a) for applied anodic potentials, thereby confirming that potential control is achieved in the measuring spot (1:1 shift).

From the $\mathrm{O} 1 \mathrm{~s}$ low BE tail in Fig. 2b, it is possible to observe that the area of the $\mathrm{Pt}-\mathrm{O}$ component (centered at $530.4 \mathrm{eV}$ ) increases as well as the adsorbed $\mathrm{OH}^{-}\left(\mathrm{OH}_{\mathrm{abs}}{ }^{-}\right.$at $\left.531.3 \mathrm{eV}\right)$.

Finally, the area of the chemisorbed water component $\left(\mathrm{H}_{2} \mathrm{O}_{\text {chem }}\right.$ centered at $\left.532.4 \mathrm{eV}\right)$ also remains constant as the potential changes from OCP to $+500 \mathrm{mV}$, with an increase under OER at $+900 \mathrm{mV}$. Interestingly, upon removing the potential ("OCP after OER"), the peak area does not appreciably change. Such observation is consistent with an increase of the electrode surface area under catalytic conditions, which will be detailed in a following section.

\section{Evolution of Pt surface chemistry as a function of the applied potential}

The Pt 4f spectra (Fig. 3) can be de-convoluted into four different spectral components: metal $\mathrm{Pt}(71.2 \mathrm{eV}), \mathrm{Pt}^{\delta}-\mathrm{OH}_{\mathrm{ads}}$ (71.8 eV), $\mathrm{Pt}^{(\mathrm{II})}(72.5 \mathrm{eV})$, and $\mathrm{Pt}^{(\mathrm{IV})}(74.6 \mathrm{eV}) .{ }^{27,41}$ Among these different components, $\mathrm{Pt}^{\delta}-\mathrm{OH}_{\text {ads }}$ provides insights into the OER mechanism at the Pt/electrolyte interface.

As proposed by Krasilshchikov ${ }^{28}$ and Damjanovic, ${ }^{24,26}$ it is well-accepted that under alkaline conditions the OER on Pt starts with the nucleophilic attack of $\mathrm{OH}^{-}$ion on $\mathrm{Pt}$ followed by a fast electron transfer to the metastable configuration where $\mathrm{OH}^{-}$is then chemisorbed on an "activated" platinum site $\left(\mathrm{Pt}^{\delta}\right) .{ }^{24,26}$ The formal positive charge of the $\mathrm{Pt}^{\delta}$ (set between $\mathrm{Pt}$ metal and $\mathrm{Pt}^{(\mathrm{II})}$ ) in the $\mathrm{Pt}^{\delta}-\mathrm{OH}_{\mathrm{ads}}$ active site, as suggested by Wagner et al., ${ }^{42}$ could explain the spectral position of its corresponding photoelectron peak, centered between the metal and $\mathrm{Pt}^{(\mathrm{II})}$ spectral components.

Interestingly, while the integrated area of this component remains unchanged with applied potentials below the OER threshold, it drastically increases under OER conditions. This finding is supported by a similar trend observed in the $\mathrm{O} 1 \mathrm{~s}$ spectrum for the $\mathrm{OH}_{\mathrm{abs}}{ }^{-}$(Fig. 2a and b). At OCP after OER, the intensity of this component is comparable to the initial OCP state. This reversibility suggests that the formation of this component is driven by high overpotentials (i.e. under OER conditions). Since oxygen evolution in alkaline environments is proceeded by the deprotonation of adsorbed $\mathrm{OH}^{-}$, we conclude that the observed spectral feature, $\mathrm{Pt}^{\delta}-\mathrm{OH}_{\mathrm{ads}}$, is representing the active species in the OER catalytic cycle.

Together with $\mathrm{Pt}^{\delta}-\mathrm{OH}_{\mathrm{ads}}$, the amount of $\mathrm{Pt}^{(\mathrm{II})}$ species increases with the applied potentials, where we observe a sharp increase once the potential is raised to $+900 \mathrm{mV}$ (OER conditions). Under this applied potential, the formation of $\mathrm{Pt}^{(\mathrm{IV})} \mathrm{O}_{2}$ oxide becomes prominent concurrently with the previously discussed Pt species (Fig. 3).
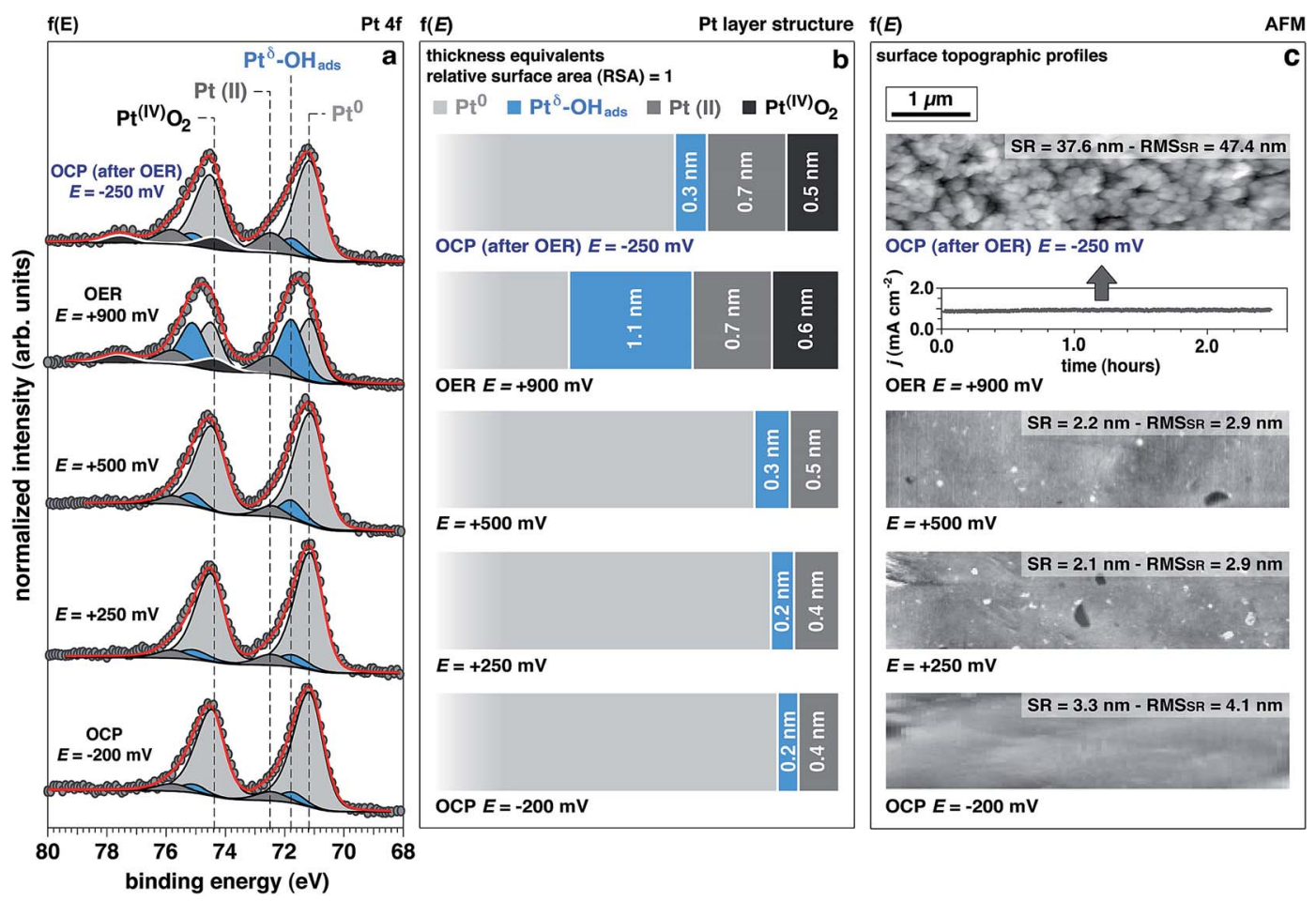

Fig. 3 Evolution of the surface chemistry studied by operando APXPS, as a function of the applied potential. (a) Pt $4 f$ spectra acquired at 4 keV as a function of the applied potential $(f(E))$ to the working electrode (from OCP to OER) (OCP: open circuit potential; OER: Oxygen evolution reaction; $\mathrm{OH}_{\text {ads }}$ : adsorbed hydroxyls). (b) Evolution of the surface structure as a function of the applied potential $(f(E))$, from OCP to OER. The numerical simulations allowed to retrieve information about the spatial localization of the different Pt chemistries. Thickness values are provided in "thickness equivalents" as the sample is not atomically flat, and the APXPS gives average information over a surface region of $300 \mu \mathrm{m}$ in diameter (OCP: open circuit potential; OER: oxygen evolution reaction); (c) peak force tapping mode ex situ AFM topographies of the Pt surface taken after 120 min resting at the reported potentials (SR: surface roughness; RMSSR: surface roughness root-mean-square). 


\section{Understanding the surface and sub-surface structure of Pt} electrode under OER conditions

Using numerical simulations of the individual Pt component photoelectron attenuation (averaged over a $300 \mu \mathrm{m}$-diameter surface area region, equal to the analyzer cone aperture), we were able to qualitatively determine the surface and sub-surface structure as a function of the applied potential (Fig. 3b). We evaluated a wide range of $\mathrm{Pt}$ species configurations ranging in thickness and relative locations, finding that the structure that best matches with the experimental data is constituted by stacked layers of Pt species. In an effort to simplify the simulations, dense layers referred to as "equivalent thickness" are used to represent the actual porosity of the Pt electrode upon OER reconstruction (see detailed explanations about the numerical procedure reported in the Experimental section and ESI Fig. $4 \dagger$ ). At OCP and increasing the potential to $+500 \mathrm{mV}$, the Pt WE possesses a sub-surface domain of $\mathrm{Pt}^{\delta}-\mathrm{OH}_{\text {ads }}$ and an outer (electrolyte facing) layer of $\mathrm{Pt}^{(\mathrm{II})}$, present in the form of $\mathrm{Pt}^{(\mathrm{II})}(\mathrm{OH})_{2}$ and $\mathrm{Pt}^{(\mathrm{II})} \mathrm{O}$. Under OER conditions at $+900 \mathrm{mV}$, the outermost layer presents an additional layer of $\mathrm{Pt}^{(\mathrm{IV})} \mathrm{O}_{2}$, while the $\mathrm{Pt}^{\delta}-\mathrm{OH}_{\mathrm{ads}}$ increases significantly. The spatial continuity between the $\mathrm{Pt}^{(\mathrm{II})}$ and the $\mathrm{Pt}^{(\mathrm{IV})}$ layers is ensured by an interfacial region of mixed $\mathrm{Pt}^{(\mathrm{II}, \text { IV) }}$ oxides. As reported in literature, ${ }^{24,25,27,43,44}$ our data and simulations confirm that the highly electroactive layer constituted by $\mathrm{Pt}^{\delta}-\mathrm{OH}_{\text {ads }}$ is localized sub-surface, between the metal substrate and a overlayer constituted by $\mathrm{Pt}^{(\mathrm{II})}$ and $\mathrm{Pt}^{(\mathrm{IV})}$ species.

The evolution of the outer surface morphology as a function of the applied potential was studied by ex situ AFM (Fig. 3c). The surface undergoes a clear reconstruction upon OER conditions transitioning from a flat metallic surface at OCP and low applied potentials (as confirmed by the low surface roughness (SR) values) to a high surface area oxidic system after catalytic conditions, characterized by a much higher SR then the pristine surface. Therefore, we believe that the so-called "gelly structure" reported in literature for Pt surfaces under OER conditions in acidic electrolytes, ${ }^{27,43,44}$ also occurs when the reaction is driven in alkaline environments. Using the previously described simulations, we can investigate the chemistry of the mesoporous ("gelly") structure, which is composed of a $\mathrm{Pt}^{(\mathrm{IV})} \mathrm{O}_{2}$ outer layer and an inner layer (on top of the $\mathrm{Pt}^{\delta}-\mathrm{OH}_{\text {ads }}$ active phase) constituted by a mixture of $\mathrm{Pt}^{(\mathrm{II})}$ phases consisting of $\mathrm{Pt}^{(\mathrm{II})}(\mathrm{OH})_{2}$ and $\mathrm{Pt}^{(\mathrm{II})} \mathrm{O}$.

\section{Experimental surface observations compared to thermodynamics predictions}

Interestingly, the measured Pt electrode properties differ drastically from the predicted $\mathrm{Pt} / \mathrm{H}_{2} \mathrm{O}$ Pourbaix diagram ${ }^{45}$ (ESI Fig. $5 \dagger)$. In alkaline conditions ( $\mathrm{pH} 13.9, \mathrm{KOH} 1.0 \mathrm{M}$ ) at the OCP, Pt should partially oxidize to a $\mathrm{Pt}^{(\mathrm{II})}(\mathrm{OH})_{2}$ phase. Upon increasing the potentials to $+250 \mathrm{mV},+500 \mathrm{mV}$, and $+900 \mathrm{mV}$ (+447 mV, +697 mV, and $+1097 \mathrm{mV} v s$. normal hydrogen electrode, respectively), the only thermodynamically stable phase the Pourbaix diagram predicts is $\mathrm{Pt}^{(\mathrm{IV})} \mathrm{O}_{2}$.

On the other hand, the experimental results clearly shows that up to $+500 \mathrm{mV} \mathrm{Pt}{ }^{\delta}-\mathrm{OH}_{\mathrm{ads}}$ and $\mathrm{Pt}^{(\mathrm{II})}$ species are present on the surface (Fig. 3). Notably, the $\mathrm{Pt}^{(\mathrm{IV})}$ spectral component is eventually observed only under the OER potential (+900 mV), therefore at a much higher potentials than the thermodynamically predicted in the Pourbaix diagram at the same $\mathrm{pH}$. Such a deviation can be due to kinetic effects that are not taken into account in a merely thermodynamic investigation of the stability of Pt phases. In addition, at OCP after OER, the surface chemistry exhibits a partial chemical hysteresis. While the $\mathrm{Pt}^{\delta}-\mathrm{OH}_{\mathrm{ads}}$ feature decreases (as a result of the potential removal, as previously discussed), it is still possible to observe both $\mathrm{Pt}^{(\mathrm{II})}$ and $\mathrm{Pt}^{(\mathrm{IV})}$ spectral fingerprints. On the contrary, the Pourbaix diagram predicts only $\mathrm{Pt}^{(\mathrm{II})}$ (present as $\mathrm{Pt}^{(\mathrm{II})}(\mathrm{OH})_{2}$ ) as the stable phase at this $\mathrm{pH}$ value.

\section{Pt surface chemistry evolution under OER conditions}

The time evolution of the $\mathrm{Pt} 4 \mathrm{f}$ spectrum and accompanying $\mathrm{Pt}^{0}$ normalized integrated areas of the $\mathrm{Pt}$ spectral components under OER conditions at $+900 \mathrm{mV}$ is reported in Fig. $4 \mathrm{a}$ and b, respectively. The same time evolution for the $\mathrm{O} 1 \mathrm{~s}$ and $\mathrm{K} 2 \mathrm{p}$ core levels is reported in ESI Fig. $6, \dagger$ together with the ionic concentration and the thickness of the electrolyte layer determined as a function of the observation time. Between 0 to 60 minutes under OER conditions we can observe the initial transitions for $\mathrm{Pt}^{\delta}-\mathrm{OH}_{\mathrm{ads}}, \mathrm{Pt}^{(\mathrm{II})}$, and $\mathrm{Pt}^{(\mathrm{IV})}$ before stabilizing and reaching steady state conditions ( $>60$ minutes). During this period, it can be seen that the $\mathrm{Pt}^{\delta}-\mathrm{OH}_{\text {ads }} / \mathrm{Pt}^{0}$ and $\mathrm{Pt}^{(\mathrm{IV})} / \mathrm{Pt}^{0}$ ratios increase accompanied by a slight decrease of the $\mathrm{Pt}^{(\mathrm{II})} / \mathrm{Pt}^{0}$ ratio with respect to time, Fig. 4 b. Using our previously established layered model, we used numerical simulations to estimate the respective "equivalent thicknesses" for each Pt phase (i) and
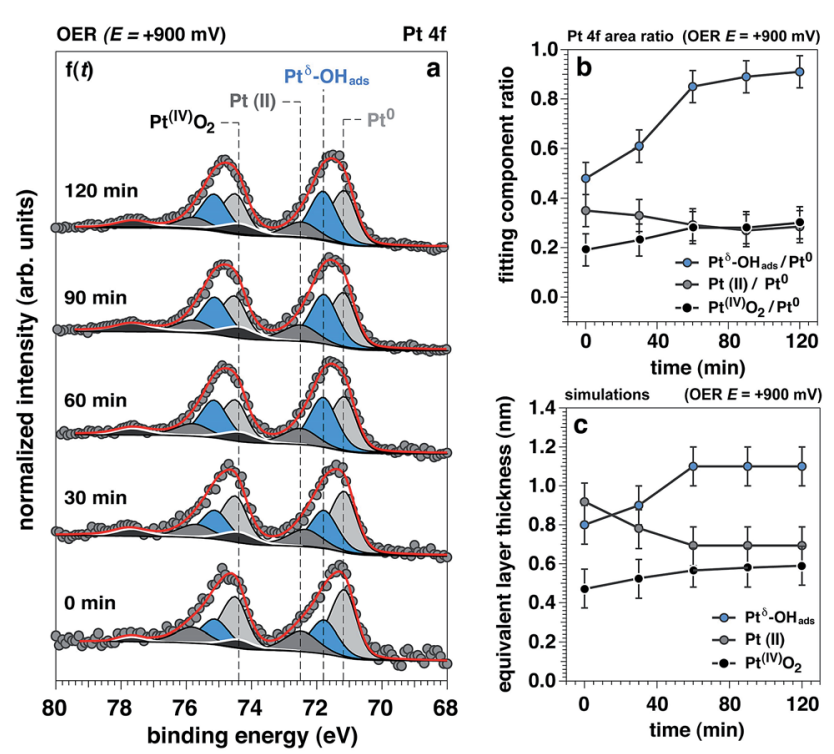

Fig. 4 Chemical and structural evolution of platinum surface under oxygen evolution conditions, as a function of time. (a) Evolution of Pt $4 \mathrm{f}$ APXPS photoelectron peak acquired at $4 \mathrm{keV}$ under oxygen evolution reaction (OER) conditions $(+900 \mathrm{mV})$, as a function of the observation time $(f(t)) ;(b, c)$ experimental trends and simulated layer thicknesses for the oxidized Pt components as a function of the observation time under OER conditions, respectively. 
retrieve their in-depth localization as a function of time under catalytic conditions (ii) (Fig. 4c).

\section{Proposed Pt structure under catalytic conditions and OER mechanism in alkaline environments}

We can now propose a more complete mechanism for platinum OER under alkaline conditions (Fig. 5) by combining our steady state and dynamic information detailed in Fig. 3 and 4 with previous literature. The mesoporosity ${ }^{27,43,44}$ of the Pt electrode (as seen in Fig. 3c and reported in ref. 27, 43 and 44) is present throughout the near surface structure, and it is composed of 3 regions. Moving from the $\mathrm{Pt}^{0}$ substrate to the outer surface, we have demonstrated the presence of $\mathrm{Pt}^{\delta}-\mathrm{OH}_{\mathrm{ads}}, \mathrm{Pt}^{(\mathrm{II})}$ species $\left(\mathrm{Pt}^{(\mathrm{II})}(\mathrm{OH})_{2}\right.$ and $\left.\mathrm{Pt}^{(\mathrm{II})} \mathrm{O}\right)$ and $\mathrm{Pt}^{(\mathrm{IV})} \mathrm{O}_{2}$. As proposed by Krasilshchikov $^{28}$ and Damjanovic ${ }^{24,26}$ for oxygen evolution on Pt in alkaline conditions, the formation of the $\mathrm{Pt}^{\delta}-\mathrm{OH}_{\text {ads }}$ phase is promoted by the nucleophilic attack of hydroxide ions to the metal Pt surface, followed by a fast electron transfer to the metastable configuration where $\mathrm{OH}^{-}$is chemisorbed on an "activated" platinum site $\left(\mathrm{Pt}^{\delta}\right) .{ }^{24,26}$ Overall, this can be rationalized by a mixed electrostatic and thermodynamic effect. As the potential applied to the WE becomes more anodic, the local increase of hydroxyl concentration (within the inner Helmholtz layer, IHL) becomes more pronounced. At the same time the high positive potential at the electrode surface lowers the Pt/ $\mathrm{OH}^{-}$surface binding energy whilst the high $\mathrm{pH}$ value (13.9) decreases the electrochemical potential of the electrolyte, ${ }^{46}$ thereby favoring the activation of the Pt surface via hydroxyl adsorption followed by the electron transfer and the consequent
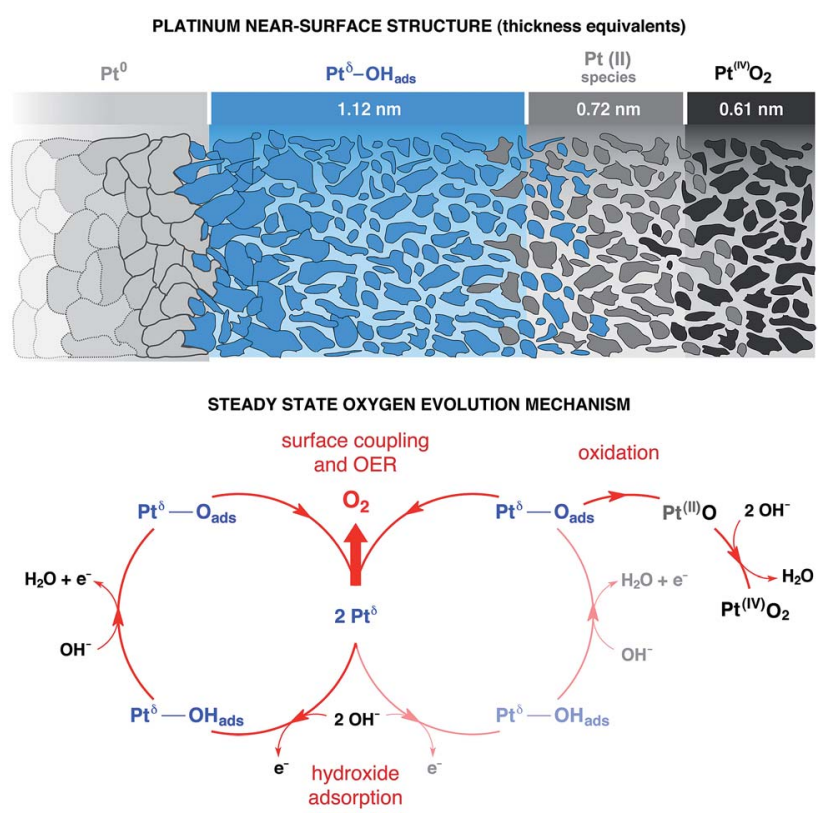

Fig. 5 Proposed catalytic mechanism and phase structure for oxygen evolution on platinum under alkaline conditions. The evaluation of the catalytic loop for oxygen evolution reaction (OER) on $\mathrm{Pt}(\mathrm{pH}$ 13.9), as well as the structural description of the catalytic state, have been performed by synergistically coupling the experimental results from the operando APXPS and the corresponding numerical simulations. formation of the $\mathrm{Pt}^{\delta}-\mathrm{OH}_{\mathrm{ads}}$ species. ${ }^{47-49}$ The final surface coupling and deprotonation of the adsorbed $\mathrm{OH}^{-}$leads to the evolution of oxygen. Interestingly, as it can be seen from the time trends reported in Fig. $4 \mathrm{~b}$ and c, only when a considerable amount of $\mathrm{Pt}^{\mathrm{\delta}}-\mathrm{OH}_{\text {ads }}$ is present on the sub-surface region the surface coupling process and the consequent $\mathrm{O}_{2}$ evolution can occur. This result is extremely important since it directly shows a kinetic limitation that contributes to the observed OER overpotential. The proposed mechanism is schematically represented in Fig. 5.

It is important to consider the possibility for $\mathrm{Pt}^{(\mathrm{IV})}$ dissolution in the form of a $\mathrm{Pt}^{(\mathrm{IV})}$ aquocomplex as indicated by the Pourbaix diagram. Based on our data, we do not observe any Pt dissolution during the potentiostatic measurements. However, one must consider that reversing (or removing) potentials could induce Pt dissolution on the order of tens of $n M$ as reported by Lopes et $a .^{15}$ The reported dissolution rates are considerably below the detection limit of the APXPS (about $100 \mathrm{mM}$ ). Therefore, although we would not be able to detect this process, a Pt dissolution cannot be excluded..$^{50,51}$

\section{Conclusions}

This study revealed the complexity and significant surface chemical reconstruction that takes place on a Pt electrode, in particular on the nature of $\mathrm{Pt}^{\delta}-\mathrm{OH}_{\text {ads }}$ species, and its crucial role on the OER mechanism. Our findings show that the presence of $\mathrm{Pt}^{\delta}-\mathrm{OH}_{\mathrm{ads}}$ is triggered by potentials within the OER region: upon removing the applied potential, the concentration of this species drops to similar values observed for the initial OCP whilst the Pt(II) and Pt(Iv) oxides chemistries remained essentially unchanged. This observation, together with the fact that the OER in alkaline conditions occurs via the oxidation of the hydroxyl, allows us to conclude that the $\mathrm{Pt}^{\delta}-\mathrm{OH}_{\text {ads }}$ constitutes the actual rate determining species for oxygen evolution. The combination of APXPS, AFM, and numerical simulations allowed us to provide new insights into the chemical structure of the Pt electrode under OER conditions, showing that the $\mathrm{Pt}^{\delta}-\mathrm{OH}_{\text {ads }}$ layer is located sub-surface. The presence of the $\mathrm{Pt}^{\delta}-\mathrm{OH}_{\text {ads }}$ layer leads to the formation of a high surface area oxidic outer layer in which $\mathrm{OH}^{-}$need to diffuse in order to activate the oxygen evolution.

This observation allows us to propose that the applied overpotential (above the thermodynamic oxidation potential of water) has two main effects. First, it positively polarizes the electrode surface, which lowers the binding energy of hydroxyl ions and increase their adsorption rate. Second, the $\mathrm{OH}^{-}$may electrostatically be driven through the oxidic porous passivation layer. ${ }^{52}$ Therefore, from the experimental observations reported here we provide motivation for reevaluating the kinetic limitations (overpotentials) of OER on Pt to take into account both adsorption/electron transfer rate and mass transport effects through the modified electrode under catalytic conditions.

Moreover, we have elucidated the differences between thermodynamic predictions of the Pt phase stability and the actual surface chemistry under polarization. The high chemical sensitivity of XPS probing the solid/liquid electrified interface 
has allowed us to re-interpret the Pourbaix diagram of Pt. Thus motivating the need for these types of operando experiments and the development of new thermodynamic, kinetic, and computational models for electrified interfaces under realistic operating conditions. ${ }^{53}$ Expanding this experimental strategy for the study of different materials and catalytic reactions under operando conditions, ${ }^{31,32,54}$ will open a path for new discoveries that will deepen our knowledge towards the accelerated development of novel tailored materials.

\section{Experimental}

\section{Dip \& pull method and operando measurements}

The three electrodes were mounted into a PEEK electrode housing that was attached to a multi-axis manipulator. Electrical feedthrough within the manipulator connected the WE, $\mathrm{RE}$, and CE to an external potentiostat/galvanostat (Biologic SP $300)$ to perform operando electrochemistry measurements. During the operation, the WE and the analyzer front cone were commonly grounded.

Prior its introduction into the experimental chamber, the electrolyte (KOH 1.0 M aqueous solution) was outgassed for at least $30 \mathrm{~min}$ at low pressure (around 10 Torr) in a dedicated offline chamber. Then, once the manipulator (Fig. 1a) and the outgassed electrolyte were placed into the APXPS experimental chamber, the pressure was carefully lowered down to the water vapor pressure (between 16 and 20 Torr, at r.t.).

To create a solid/liquid interface (WE/electrolyte), all three electrodes were immersed into the electrolyte. Then they were slowly extracted from the electrolyte solution by rising the manipulator at a constant vertical rate. Following this procedure, a thin layer of liquid electrolyte film is formed on the $\mathrm{Pt}$ electrode (typical values ranges between 10 and $30 \mathrm{~nm}$ ); the three electrodes were then positioned at the focal point of the analyzer, giving the possibility of performing XPS investigation of the solid/liquid interface as a function of the applied potential. During the measurements, the bottom parts of the electrodes were kept into the bulk electrolyte, in order to ensure electrical continuity between the thin electrolyte layer on the WE surface and the bulk electrolyte itself.

\section{Electrochemical measurements}

The chemicals employed here were high purity reagents and they were used as received without further operations. MilliQ water (DI, $\rho=18.2 \mathrm{M} \Omega \mathrm{cm}$ ) and potassium hydroxide $(\mathrm{KOH}$, 99.99\%, Aldrich) were used as solvent and supporting electrolyte, respectively.

The working (WE) and counter electrodes (CE, Pt polycrystalline foils, 99.99\%, thickness $0.5 \mathrm{~mm}$, Aldrich) were polished to a mirror finish with silicon carbide papers of decreasing grain size (Struers, grit: 2400 and 4000). The samples were then cleaned by two cycles of ultrasonic treatment in a mixture of MilliQ water/ethanol (Aldrich, $1: 1$ ) for $10 \mathrm{~min}$. A third ultrasonic cleaning was then conducted in pure MilliQ water for $15 \mathrm{~min}$, followed by a thoroughly rinsing and drying in $\mathrm{N}_{2}$ stream. As reference electrode (RE), a miniaturized leakless
$\mathrm{Ag} / \mathrm{AgCl} / \mathrm{Cl}_{(\text {sat.) }}{ }^{-} \mathrm{RE}$ (ET072-1, eDAQ) was used (standard electrode potential $E_{\mathrm{Ag} / \mathrm{AgCl}_{(\mathrm{sat})}^{\circ}}=197 \mathrm{mV}$ with respect to the normal hydrogen electrode, NHE). All the potentials reported in this work are referred to this RE unless differently stated.

An electrochemical cleaning procedure was conducted by holding the Pt WE at $-1200 \mathrm{mV}$ (within the HER region) for 30 minutes, in order to obtain a pure metallic surface and a homogeneous surface, increasing in this way the experimental reproducibility. The cleaning procedure was stopped after reaching the current open circuit potential (OCP) of the cell from the cathodic side. The data acquisition started only when the OCP reached a stable value over the observation time (about 30 minutes). All the voltammetric measurements were conducted at a scan rate of $20 \mathrm{mV} \mathrm{s}^{-1}$.

Electrochemical impedance spectroscopy (EIS) measurements were carried out with the aim of electrochemically evaluate the interfacial properties of the solid/liquid interface. EIS measurements were conducted by measuring the response in current after applying to the WE a sinusoidal wave of potential of $10 \mathrm{mV}$ peak-to-peak voltage amplitude, at OCP $(-200 \mathrm{mV})$ and OER conditions $(+900 \mathrm{mV})$. The frequency of the sinusoidal potential wave was ranging from $105 \mathrm{~Hz}$ to $5 \mathrm{mHz}$, scanning 10 frequencies per decade.

\section{Beamline 9.3.1 and APXPS experimental details}

Beamline 9.3.1 at Advanced Light Source (ALS, Lawrence Berkeley National Laboratory) is equipped with a bending magnet and a Si (111) double crystal monochromator (DCM) having a total energy range between $2.0 \mathrm{keV}$ and $7.0 \mathrm{keV}$ ("tender" X-ray range). The minimal spot size at the beamline is $0.7 \mathrm{~mm}(\mathrm{v}) \times$ $1.0 \mathrm{~mm}(\mathrm{~h})$.

For the data acquisition, the pass energy of the Scienta analyzer (R4000 HiPP-2) was set to $200 \mathrm{eV}$, using a step of 100 $\mathrm{meV}$ and a dwell time of $300 \mathrm{~ms}$. Under these conditions, the total resolution (X-rays and analyzer) was equal to about 250 $\mathrm{meV}$ at room temperature (r.t.) and at $4 \mathrm{keV}$. The measurements were taken using a photon energy of $4 \mathrm{keV}$ at r.t. and in normal emission ( $\mathrm{NE}$ ), at a pressure in the experimental chamber matching the water vapor tension at r.t., between 16 and 18 Torr. The detection stage in the analyzer (multichannel plate, MCP) was under high vacuum conditions $\left(\sim 10^{-7}\right.$ Torr $)$ throughout the all experiment, thanks to the differentially pumped electrostatic lens system based on four independent pumping stages. To limit the evaporation from the electrochemical cell we place a larger outgassed solution buffer in the analysis chamber to facilitate the fully humidified environment at room temperature. The calibration of the binding energy (BE) scale was carried out using the Au $4 \mathrm{f}$ photoelectron peak as reference $\left(4 \mathrm{f}_{7 / 2} \mathrm{BE}=84.0 \mathrm{eV}\right)$ as well as the Fermi edge, from a clean gold polycrystalline surface measured under all the investigated experimental conditions.

All the fit reported in this work have been carried out using a Doniach-Šunjic shape for the $\mathrm{Au}$ and $\mathrm{Pt} 4 \mathrm{f}$ photoelectron peaks, whereas a symmetrical Voigt function $(G / L$ ratio ranging from $85 / 15$ to $75 / 25$ ) was used to fit the $O$ 1s photoelectron peaks (after Shirley background subtraction). ${ }^{36}$ During the 
fitting procedure, the Shirley background was optimized as well together with the photoelectron intensity of the spectral components, increasing in this manner the precision and reliability of the fitting procedure..$^{36,55,56}$ The $\chi^{2}$ minimization was ensured by the use of a nonlinear least squares routine, with increased stability over simplex minimization. ${ }^{36,55,56}$

\section{Atomic force microscopy characterization}

AFM measurements were performed under ambient condition using a Bruker Dimension Icon AFM and rectangular silicon cantilevers (RFESP-75, Bruker). Nanometer scale lateral resolution images of surface topography were acquired in peak force (PF) tapping mode at $2 \mathrm{kHz}$ modulation with a PF amplitude of $150 \mathrm{~nm}$. The linear scan rate was set to $0.3 \mathrm{~Hz}$ with scan resolution of 256 samples per line. For the applied peak force a maximum value of $40 \mathrm{nN}$ was used to avoid damaging the sample or wearing the tip.

Data processing of the raw images was performed using customized Igor procedures.

\section{Numerical simulations of the photoelectron intensity}

The numerical simulations of the photoelectron intensity were developed used SESSA software. Technical details and examples of the potentialities of this tool can be found in ref. 57-60.

From observations already reported in literature about the oxidic surface structure of Pt under OER conditions, ${ }^{27,44}$ the simulations were built adopting a conformal layer-by-layer structure "buried" underneath an electrolyte (KOH 1.0 M) film characterized by an average thickness of $21.3 \pm 0.9 \mathrm{~nm}$. Three crucial aspects needs to be highlighted:

- The simulations were performed using net and well-defined layer/layer interfaces. This is an approximation of the real configuration, where most likely gradients and mixed regions may exist at the layer/layer interfaces. However, the spatial extension of such regions are typically of about 1-2 $\mathrm{nm}$, a dimension that is typically difficult to access and discriminate with tender X-rays. Therefore, the approximation used here is reasonable at the light of the features offered by the APXPS technique;

- The simulations were conducted by using the well-known growth modes: layer-by-layer or Frank-Van der Merwe, layerisland or Stranski-Krastanov and island formation or VolmerWeber. ${ }^{\mathbf{6 1 , 6 2}}$ Moreover, for a chosen model, we have investigated different spatial localization of the oxidized Pt chemistries (see summary reported in ESI Fig. $4 \dagger$ ). The model that fitted better with the experimental simulations was found by using a chisquare $\left(\chi^{2}\right)$ statistical test. The quantities used for its evaluation were the $\mathrm{Pt}^{\delta}-\mathrm{OH}_{\text {ads }} / \mathrm{Pt}^{0}\left(R_{1}\right)$, $\mathrm{Pt}(\mathrm{II}) / \mathrm{Pt}^{0}\left(R_{2}\right)$ and $\mathrm{Pt}^{(\mathrm{IV})} \mathrm{O}_{2} / \mathrm{Pt}^{0}$ $\left(R_{3}\right)$ ratios, determined experimentally through the multipeak fitting procedure of $\mathrm{Pt} 4 \mathrm{f}$ photoelectron peak (EXP) and from the numerical simulations (SIM). Therefore:

$$
\chi^{2}=\sum_{i=1,2,3}^{\alpha, \beta}\left(R_{i}^{\mathrm{EXP}}-R_{i}^{\mathrm{SIM}}\right)^{2},
$$

where $\alpha$ and $\beta$ indicates a particular model and its configuration (thickness of the constituting layers).
For the final evaluation of model/configuration, the space of parameters was explored using a variational principle: for each model, the minimum value of the $\chi^{2}$ was achieved by properly adjusting the layer thickness of the different oxidized Pt species. This procedure allows to determine both the structure and the corresponding configuration (layer thicknesses) that best match with the experimental results;

- The relative surface area (RSA) for the top most layer in the calculations have been derived directly from the experimental ex situ AFM surface characterizations reported in Fig. 3.

\section{Author contributions}

The manuscript was written through contributions of all authors. M. F. planned and executed the operando APXPS experiments and the numerical simulations, evaluated the data and drafted the manuscript. E. J. C. and Z. L. conceived and supervised the study and drafted the manuscript. C. V. V. performed the EIS analysis, while J. E. performed the AFM characterizations. P. N. R., J. Y. and F. M. T. gave general advisory and actively participated in drafting the manuscript. All authors have given approval to the final version of the manuscript.

\section{Conflict of interest}

The authors declare no competing financial interests.

\section{Acknowledgements}

This work was partially supported through the Office of Science, Office of Basic Energy Science (BES), of the U.S. Department of Energy (DOE) under award no. DE-SC0004993 to the Joint Center for Artificial Photosynthesis (JCAP), a DOE Energy Innovation Hub. This work was also supported by the National Natural Science Foundation of China (11227902). The Advanced Light Source is supported by the Director, Office of Science, Office of Basic Energy Sciences, of the U.S. Department of Energy under Contract No. DE-AC02-05CH11231. J. E. and F. M. $\mathrm{T}$ acknowledge support by the Laboratory Directed Research and Development Program of Lawrence Berkeley National Laboratory under U.S. Department of Energy contract number DE-AC02-05CH11231.

\section{References}

1 N. S. Lewis and D. G. Nocera, Proc. Natl. Acad. Sci. U. S. A., 2006, 103, 15729-15735.

2 J. R. McKone, N. S. Lewis and H. B. Gray, Chem. Mater., 2013, 26, 407-414.

3 L. Carrette, K. A. Friedrich and U. Stimming, Fuel cells, 2001, 1, 5-39.

4 W. Yu, M. D. Porosoff and J. G. Chen, Chem. Rev., 2012, 112, 5780-5817.

5 Z. Chen, D. Higgins, A. Yu, L. Zhang and J. Zhang, Energy Environ. Sci., 2011, 4, 3167-3192.

6 R. Schlögl, Angew. Chem., Int. Ed., 2015, 54, 3465-3520. 
7 B. K. Carpenter, J. N. Harvey and A. J. Orr-Erwing, J. Am. Chem. Soc., 2016, 138, 4695-4705.

8 B. E. Conway and T. C. Liu, Langmuir, 1990, 6, 268-276.

9 N. M. Markovic, H. A. Gasteiger and P. N. Ross, J. Phys. Chem., 1996, 100, 6715-6721.

10 V. Stamenkovic, B. S. Mun, K. J. J. Mayrhofer, P. N. Ross, N. M. Markovic, J. Rossmeisl, J. Greeley and J. K. Nørskov, Angew. Chem., Int. Ed., 2006, 118, 2963-2967.

11 W. Sheng, H. A. Gasteiger and Y. Shao-Horn, J. Electrochem. Soc., 2010, 157, B1529-B1536.

12 I. E. L. Stephens, A. S. Bondarenko, F. J. Perez-Alonso, F. Calle-Vallejo, L. Bech, T. P. Johansson, A. K. Jepsen, R. Frydendal, B. P. Knudsen, J. Rossmeisl and I. Chorkendorff, J. Am. Chem. Soc., 2011, 133, 5485-5491.

13 T. Reier, M. Oezaslan and P. Strasser, ACS Catal., 2012, 2, 1765-1772.

14 I. E. L. Stephens, A. S. Bondarenko, U. Grønbjerg, J. Rossmeisl and I. Chorkendorff, Energy Environ. Sci., 2012, 5, 6744-6762.

15 P. P. Lopes, D. Strmcnik, D. Tripkovic, J. G. Connell, V. Stamenkovic and N. M. Markovic, ACS Catal., 2016, 6, 2536-2544.

16 D. Strmcnik, M. Uchimura, C. Wang, R. Subbaraman, N. Danilovic, D. Van der Vliet, A. P. Paulikas, V. Stamenkovic and N. M. Markovic, Nat. Chem., 2013, 5, 300306.

17 P. Hernandez-Fernandez, F. Masini, D. N. McCarthy, C. E. Strebel, D. Friebel, D. Deiana, P. Malacrida, A. Nierhoff, A. Bodin, A. M. Wise, J. H. Nielsen, T. W. Hansen, A. Nilsson, I. E. L. Stephens and I. Chorkendorff, Nat. Chem., 2014, 6, 732-738.

18 D. Strmcnik, K. Kodama, D. Van Der Vliet, J. Greeley, V. R. Stamenkovic and N. M. Markovic, Nat. Chem., 2009, 1, 466-472.

19 D. Strmcnik, V. Tripkovic, D. Van Der Vliet, K.-C. Chang, V. Komanicky, H. You, G. Karapetrov, J. P. Greeley, V. R. Stamenkovic and N. M. Markovic, J. Am. Chem. Soc., 2008, 130, 15332-15339.

20 L. Gan, C. Cui, M. Heggen, F. Dionigi, S. Rudi and P. Strasser, Science, 2014, 346, 1502-1506.

21 M. Escudero-Escribano, P. Malacrida, M. H. Hansen, U. G. Vej-Hansen, A. Velazquez-Palezuela, V. Tripkovic, J. Schiøtz, J. Rossmeisl, I. E. L. Stephens and I. Chorkendorff, Science, 2016, 352, 73-76.

22 P. P. Lopes, D. Strmcnik, J. S. Jirkovsky, J. G. Connell, V. Stamenkovic and N. M. Markovic, Catal. Today, 2016, 262, 41-47.

23 L. F. Sallum, E. R. Gonzalez and J. M. Feliu, Electrochem. Commun., 2016, 72, 83-86.

24 A. Damjanovic, A. Dey and J. O. 'M. Bockris, Electrochim. Acta, 1966, 11, 791-814.

25 D. Gilroy and B. E. Conway, Can. J. Chem., 1968, 46, 875-890.

26 I. V. Birss and A. Damjanovic, J. Electrochem. Soc., 1987, 134, 113-117.

27 R. Arrigo, M. Hävecker, M. E. Schuster, C. Ranjan, E. Stotz, A. Knop-Gericke and R. Schlögl, Angew. Chem., Int. Ed., 2013, 52, 1-6.
28 A. L. Krasilshchikov, Zh. Fiz. Khim., 1963, 37, 531.

29 N. Danilovic, R. Subbaraman, K.-C. Chang, S.-H. Chang, Y. J. Kang, J. Snyder, A. P. Paulikas, D. Strmcnik, Y.-T. Kim, D. Myers, V. Stamenkovic and N. M. Markovic, J. Phys. Chem. Lett., 2014, 5, 2474-2478.

30 Y. Surendranath, M. W. Kanan and D. G. Nocera, J. Am. Chem. Soc., 2010, 132, 16501-16509.

31 E. J. Crumlin, Z. Liu, H. Bluhm, W. Yang, J. Guo and Z. Hussain, J. Electron Spectrosc. Relat. Phenom., 2015, 42, 264-273.

32 H.-J. Lewerenz, M. F. Lichterman, M. H. Richter, E. J. Crumlin, S. Hu, S. Axnanda, M. Favaro, W. Drisdell, Z. Hussain, B. S. Brunschwig, A. Nilsson, A. Bell, N. S. Lewis and D. Friebel, Electrochim. Acta, 2016, 211, 711-719.

33 Y. T. Law, S. Zafeiratos, S. G. Neophytides, A. Orfanidi, D. Costa, T. Dintzer, R. Arrigo, A. Knop-Gericke, R. Schloegl and E. R. Savinova, Chem. Sci., 2015, 6, 56355642.

34 Z. Zhu, F. Tao, F. Zheng, R. Chang, Y. Li, L. Heinke, Z. Liu, M. Salmeron and G. A. Somorjai, Nano Lett., 2012, 12, 1491-1497.

35 S. Axnanda, E. J. Crumlin, B. Mao, S. Rani, R. Chag, P. G. Karlsson, M. O. M. Edwards, M. Lundqvist, R. Moberg, P. N. Ross, Z. Hussein and Z. Liu, Sci. Rep., 2015, 5, 9788.

36 M. Favaro, B. Jeong, P. N. Ross, J. Yano, Z. Hussain, Z. Liu and E. J. Crumlin, Nat. Commun., 2016, 7, 12695.

37 M. Pourbaix, National Association of Corrosion Engineers, 1974.

38 C. A. Tolman, Chem. Soc. Rev., 1972, 1, 337-353.

39 M. F. Lichterman, S. Hu, M. H. Richter, E. J. Crumlin, S. Axnanda, M. Favaro, W. Drisdell, Z. Hussein, T. Mayer, B. S. Brunschwig, N. S. Lewis, Z. Liu and H.-J. Lewerenz, Energy Environ. Sci., 2015, 8, 2409-2416.

40 A. Eilert, F. Cavalca, F. S. Roberts, J. Osterwalder, C. Liu, M. Favaro, E. J. Crumlin, H. Ogasawara, D. Friebel, L. G. M. Pettersson and A. Nilsson, J. Phys. Chem. Lett., 2017, 8, 285-290.

41 V. A. Saveleva, V. Papaefthimiou, M. K. Daletou, W. H. Doh, C. Ulhaq-Buillet, M. Diebold, S. Zaiferatos and E. R. Savinova, J. Phys. Chem. C, 2016, 120, 15930-15940.

42 F. T. Wagner and T. E. Moylan, Surf. Sci., 1987, 191, 121-146. 43 M. Peuckert and H. Ibach, Surf. Sci., 1984, 136, 319-326.

44 A. E. Bolzan and A. J. Arvia, J. Electroanal. Chem., 1994, 375, 157-162.

45 The thermodynamic predictions of the stability of the different Pt species as a function of applied potential and pH have been determined by simulating the corresponding Pourbaix diagram with the Materials Project facility A. Jain, S. P. Ong, G. Hautier, W. Chen, W. D. Richards, S. Dacek, S. Cholia, D. Gunter, D. Skinner, G. Ceder and K. A. Persson, APL Mater., 2013, 1, 011002; A. Jain, G. Hautier, S. P. Ong, C. Moore, C. Fischer, K. Persson and G. Ceder, Phys. Rev. B: Condens. Matter Mater. Phys., 2011, 84, 045115. 
46 P. Daubinger, J. Kieninger, T. Unmüssig and G. A. Urban, Phys. Chem. Chem. Phys., 2014, 16, 8392-8399.

47 G. B. Fisher and B. A. Sexton, Phys. Rev. Lett., 1980, 44, 683686.

48 A. V. Melo, W. E. O'Grady, G. S. Chottiner and R. W. Hoffman, Appl. Surf. Sci., 1985, 21, 160-167.

49 S. Yamamoto, H. Bluhm, K. Andersson, G. Ketteler, H. Ogasawara, M. Salmeron and A. Nilsson, J. Phys.: Condens. Matter, 2008, 20, 184025.

50 T. Binninger, R. Mohamed, K. Waltar, E. Fabbri, P. Levecque, R. Kötz and T. J. Schmidt, Sci. Rep., 2015, 5, 12167.

51 H. Dau, C. Limberg, T. Reier, M. Risch, S. Roggan and P. Strasser, ChemCatChem, 2010, 2, 724-761.

52 J. Yang, J. K. Cooper, F. M. Toma, K. A. Walczak, M. Favaro, J. W. Beeman, L. H. Hess, C. Wang, C. Zhu, S. Gul, J. Yano, C. Kisielowski, A. Schwartzberg and I. D. Sharp, Nat. Mater., DOI: 10.1038/nmat4794.

53 F. M. Toma, J. K. Cooper, V. Kunzelmann, M. T. McDowell, J. Yu, D. M. Larson, N. J. Borys, C. Abelyan, J. W. Beeman, K. M. Yu, J. Yang, L. Chen, M. R. Shaner, J. Spurgeon,
F. A. Houle, K. A. Persson and I. D. Sharp, Nat. Commun., 2016, 7, 12012.

54 M. Favaro, W. S. Drisdell, M. A. Marcus, J. M. Gregoire, E. J. Crumlin, J. A. Haber and J. Yano, ACS Catal., 2017, 7, 1248-1258.

55 S. Evans, Surf. Interface Anal., 1991, 17, 85-93.

56 J. Muñoz-Flores and A. Herrera-Gomez, J. Electron Spectrosc. Relat. Phenom., 2012, 184, 533-541.

57 W. Smekal, W. S. M. Werner and C. J. Powell, Surf. Interface Anal., 2005, 37, 1059-1067.

58 S. Techane, D. R. Baer and D. G. Castner, Anal. Chem., 2011, 83, 6704-6712.

59 W. S. M. Werner, M. Chudzicki, W. Smekal and C. J. Powell, Appl. Phys. Lett., 2014, 104, 233106.

60 W. S. M. Werner, W. Smekal, T. Hisch, J. Himmelsbach and C. J. Powell, J. Electron Spectrosc. Relat. Phenom., 2013, 190, 137-143.

61 H. Brune, H. Röder, C. Boragno and K. Kern, Phys. Rev. Lett., 1994, 73, 1955-1958.

62 K. Bromann, H. Brune, H. Röder and K. Kern, Phys. Rev. Lett., 1995, 75, 677-680. 